\title{
BMJ Open How are clinical commissioning groups managing conflicts of interest under primary care co-commissioning in England? A qualitative analysis
}

\author{
Valerie Moran, ${ }^{1}$ Pauline Allen, ${ }^{1}$ Imelda McDermott, ${ }^{2}$ Kath Checkland, ${ }^{2}$ \\ Lynsey Warwick-Giles, ${ }^{2}$ Oz Gore, ${ }^{3}$ Donna Bramwell, ${ }^{3}$ Anna Coleman ${ }^{2}$
}

To cite: Moran V, Allen $P$, McDermott I, et al. How are clinical commissioning groups managing conflicts of interest under primary care co-commissioning in England? A qualitative analysis. BMJ Open 2017;7:e018422. doi:10.1136/ bmjopen-2017-018422

- Prepublication history for this paper is available online. To view these files, please visit the journal online (http://dx.doi. org/10.1136/bmjopen-2017018422).

Received 27 June 2017 Revised 31 August 2017 Accepted 4 September 2017

\section{CrossMark}

${ }^{1}$ Department of Health Services Research and Policy, London School of Hygiene and Tropical Medicine, London, UK

${ }^{2}$ Division of Population Health, Health Services Research and

Primary Care, University of

Manchester, Manchester, UK

${ }^{3}$ Division of Population Health, Health Services Research and Primary Care and Alliance

Manchester Business School, University of Manchester, Manchester, UK

Correspondence to Dr Valerie Moran; valerie.moran@Ishtm.ac.uk

\section{ABSTRACT}

Objectives From April 2015, NHS England (NHSE) started to devolve responsibility for commissioning primary care services to clinical commissioning groups (CCGs). The aim of this paper is to explore how CCGs are managing potential conflicts of interest associated with groups of GPs commissioning themselves or their practices to provide services.

Design We carried out two telephone surveys using a sample of CCGs. We also used a qualitative case study approach and collected data using interviews and meeting observations in four sites (CCGs).

Setting/participants We conducted 57 telephone interviews and 42 face-to-face interviews with general practitioners (GPs) and CCG staff involved in primary care cocommissioning and observed 74 meetings of CCG committees responsible for primary care co-commissioning.

Results Conflicts of interest were seen as an inevitable consequence of CCGs commissioning primary care. Particular problems arose with obtaining unbiased clinical input for new incentive schemes and providing support to GP provider federations. Participants in meetings concerning primary care co-commissioning declared conflicts of interest at the outset of meetings. Different approaches were pursued regarding GPs involvement in subsequent discussions and decisions with inconsistency in the exclusion of GPs from meetings. CCG senior management felt confident that the new governance structures and policies dealt adequately with conflicts of interest, but we found these arrangements face limitations. While the revised NHSE statutory guidance on managing conflicts of interest (2016) was seen as an improvement on the original (2014), there still remained some confusion over various terms and concepts contained therein.

Conclusions Devolving responsibility for primary care co-commissioning to CCGs created a structural conflict of interest. The NHSE statutory guidance should be refined and clarified so that CCGs can properly manage conflicts of interest. Non-clinician members of committees involved in commissioning primary care require training in order to make decisions requiring clinical input in the absence of GPs.

\section{BACKGROUND}

A conflict of interest is a set of circumstances that creates a risk that an individual's ability to apply judgement or
Strengths and limitations of this study

- The first study investigating conflicts of interest for clinical commissioning groups (CCGs) commissioning primary care services.

- In-depth case studies of four CCGs nationally.

- We complemented four in-depth case studies with a national telephone survey.

- Analysis of all CCG primary care co-commissioning application documents.

- Telephone survey was a snapshot in time (twice), but we achieved a good response rate.

act in one role is, or could be, impaired or influenced by a secondary interest. ${ }^{1}$

The Health and Social Care Act 2012 substantially reorganised the commissioning system in England, creating general practitioner (GP)led clinical commissioning groups (CCGs) with responsibility for commissioning the majority of secondary and community care services. Responsibility for commissioning primary care services was given to a new national body, NHS England (NHSE), partly to avoid the conflicts of interest associated with groups of GPs commissioning themselves or their practices to provide services. From 1 April 2015, NHSE started devolving this responsibility to CCGs. This policy change was motivated by CCGs' knowledge of local population health needs and their assumed ability to commission integrated pathways. These benefits were seen as outweighing the risks of conflicts of interest.

In 2014/2015, prior to the transfer of responsibility for commissioning primary care services to CCGs, the National Audit Office (NAO) undertook an investigation into the management of conflicts of interests by CCGs in response to Parliamentary and public concerns. The investigation consisted of interviews with the Department of Health, 
NHSE and Monitor, document review, visits to two CCGs and the collection of information from all CCG websites. The resulting report was published in September $2015 .^{2}$

The report highlighted the potential for conflicts of interest, in particular when GPs are likely to be providers of services commissioned by CCGs. The NAO expected the risk of conflicts of interest to increase with the introduction of primary care co-commissioning and raised concerns about the ability of NHSE to respond adequately to this increase. The NAO reviewed the policies and processes CCGs introduced during 2014/2015 to meet legislative requirements to prevent and manage conflicts of interest. These included the appointment of lay members to the CCG governing body (GB), publication of GB meeting papers and minutes and online publication of registers of interest for GB members. Although a minority of CCGs reported they had to manage actual or perceived conflicts of interest during 2014/2015, it was not always evident from publicly available information how these conflicts of interests were managed by CCGs. The report also highlighted variation between CCGs in the perceived adequacy of controls for managing conflicts of interest.

This paper adds to the NAO report in a number of ways. Most importantly, our research commenced in 2015, after CCGs took on responsibility for commissioning primary care. This allowed us to observe the effectiveness of the processes and structures CCGs put in place to respond to the increased risk of conflicts of interest. Second, we collected rich and detailed primary data using a combination of an in-depth case study approach of four CCGs nationally and two telephone surveys of a sample of CCGs.

\section{Agency theory and corporate governance}

Agency theory provides a useful framework to understand why conflicts of interest arise in the context of CCGs commissioning primary care. Jensen and Meckling ${ }^{3}$ define an agency relationship as a contract whereby a principal delegates specific activities to an agent to undertake on their behalf. The delegation of responsibilities will be unproblematic if the principal has full information or if the objectives of the principal correspond to those of the agent. ${ }^{4}$ However, if both the principal and the agent seek to maximise their own utility, then the interests of the agent are likely to diverge from those of the principal. ${ }^{3}$ This leads to an agency problem, or conflict of interest. ${ }^{5}$ The principal can limit the extent to which the agent acts in his own interest by creating appropriate incentives for the agent and by monitoring the activities of the agent. ${ }^{3}$

In the corporate world, company shareholders can be viewed as principals who delegate responsibility for managing the company to an agent-the board. Monitoring management activity is costly, and all shareholders can potentially benefit from monitoring activities carried out by only one shareholder. This leads to an incentive for shareholders to free ride on the activities of other shareholder(s), and this in turn reduces the likelihood that any individual shareholder(s) will undertake monitoring activities. ${ }^{5}$ This lack of monitoring, allied with the separation between ownership and control, can lead to conflicts of interest if management pursue their own interests at the expense of shareholders. ${ }^{5-7}$

In the context of primary care co-commissioning, an analogy can be drawn between the board of directors and GPs. CCGs are agents acting on behalf of NHSE (the principal), which carries statutory responsibility for spending public funds, acting as a proxy for taxpayers. In their primary care commissioning role, GPs assume a stewardship function for those funds, from which they could potentially benefit financially, non-financially (personal or professional) or indirectly. In the absence of adequate monitoring by NHSE or a proxy, GPs have a potential conflict of interest if they pursue their own interests, which diverge from those of NHSE.

In business, corporate governance mechanisms act to align the interests of shareholders and management and limit undesirable behaviour on the part of management. ${ }^{7}$ These governance structures include the prohibition of actions and decisions leading to self-dealing, the use of independent boards and chairs, ${ }^{89}$ an environment encouraging disclosure, which serves to overcome information asymmetry between the principal and agent, ${ }^{10}$ peer pressure and ethics training. ${ }^{11}$

Company shareholders elect a board of directors to act on their behalf. In the UK, the report of 'The Committee on the Financial Aspects of Corporate Governance ${ }^{12}$ outlined a number of important recommendations for the composition of boards and associated committees including:

- The separation of the roles of chief executive and chairman of the board

- The majority of the board should comprise independent or non-executive directors, selected by a formal process for a fixed term.

A key role of the board of directors is to monitor executive management and ensure that the company is run in the best interests of shareholders. ${ }^{568913}$ Nolan $^{8}$ asserts that suitably skilled and motivated independent or non-executive directors are ideal for monitoring and controlling the potential conflicts of interest of executive directors as, unlike shareholders, non-executive directors have a continuous involvement in the governance of the company and do not face the problem of collective action due to the public good nature of shareholder monitoring. Lay members of CCG decision-making committees are akin to non-executive directors in that they provide an external view of the work of the CCG that is impartial and strategic, and they are removed from the day-to-day running of the organisation. ${ }^{14}$

Nevertheless, these corporate governance mechanisms are not without limitations. Boards of directors are often regarded as being too close to management and unable to apply proper scrutiny of decisions due to an inability to fully comprehend complex financial affairs. ${ }^{6}{ }^{9}$ Hart $^{5}$ draws attention to the shortcomings of non-executive directors as effective monitors of executive directors. 
Namely, the former may have little personal gain from improved company performance, have busy schedules and may have undue loyalty to managers who put them in these positions and pay their fees. Cafaggi ${ }^{13}$ asserts that there is a trade-off between the impartiality of non-executive directors and accountability, reflecting the tenuous link between the interests of independent directors and shareholders. Moreover, the independence of non-executive directors should be subject to monitoring and intermittent inspection as it is not necessarily a static quality. There is an onus on non-executive board members to monitor each other, but this can present difficulties due to the relationships that arise among peers and the influential role of subordinate management, particularly in influencing relationships among independent directors. ${ }^{13}$

Simply disclosing a conflict of interest is viewed as inadequate without effective monitoring of management's conduct and compliance ${ }^{813}$ ideally by independent, non-executive directors. ${ }^{8}$ Disclosure can aggravate the effects of conflicts of interest by generating bias. ${ }^{15} 16$ This is because the conflicted individual anticipates that their judgement will be discounted after disclosure, and they respond by strategically exaggerating their judgements in anticipation of this subsequent discounting. This implies that disclosure of a conflict of interest amplifies rather than alleviates bias. ${ }^{15}$ Moreover, there is evidence that recipients of biased advice do not discount it as much as they should following disclosure. ${ }^{16}$

\section{NHSE statutory guidance on conflicts of interest for CCGs}

In December 2014, NHSE published statutory guidance for CCGs on conflicts of interest, to take effect on 1 April 2015 when CCGs could take on additional responsibility for primary care commissioning. ${ }^{17}$ This replaced guidance for CCGs on managing conflicts of interest published by NHSE in 2013. The new 2014 guidance recognised that by taking on responsibility for commissioning primary care, CCGs would expose themselves to a greater risk of both real and perceived conflicts of interest. This necessitated a strengthening of the existing guidance. CCGs had to verify that they had plans in place to comply with the guidance when they applied to take on delegated or joint commissioning responsibilities, as well as during the annual CCG performance-assessment process.

NHSE updated the 2014 guidance in June $2016^{18}$ following a co-commissioning conflicts of interest audit in $2015 / 2016,{ }^{19}$ the NAO report on the management of conflicts of interest in $\mathrm{CCGs}^{2}$ and feedback from a public consultation exercise. The revised guidance recognised that conflicts of interest are inevitable and need to be managed appropriately in order to assure the public, providers and Parliament of the fairness and robustness of CCG decisions and that they are transparent and offer value for money. The expressed purposes of the revised guidance included: supporting the understanding and management of conflicts of interest among commissioners; enabling commissioners to act fairly and transparently in the best interests of their patients and the local population; and maintaining public confidence in the NHS. More specifically, the document guided CCGs on:

- How to identify and manage conflicts of interest.

- Declarations of interests.

- The maintenance of registers of interests.

- Appointments and roles and responsibilities within the CCG.

- The management of conflicts of interest at meetings and throughout the commissioning cycle.

- The role of the internal audit.

- Procedure in the case of breaches of the guidance.

- The impact of non-compliance.

- Conflicts of interest training.

The revised guidance $^{18}$ expanded on some areas addressed in the original guidance such as registers of interest, governance and decision-making processes and procurement. The key changes in the revised guidance were:

- The appointment of a minimum of three lay members to the CCG GB.

- The appointment a conflicts of interest guardian.

- The inclusion of a robust process for managing breaches of the conflicts of interest policy and publication of anonymised details of the breach on the CCG's website.

- Strengthened provisions for decision making when a committee member has a conflict including:

- Advising that the chair proactively consider potential conflicts of interest and how they should be managed prior to the meeting and take appropriate steps such as ensuring the conflicted member is not sent meeting papers related to the conflicted item;

- Advising that the chair ask for declarations of interest at the beginning of a meeting and that committee members alert the chair to a potential conflict of interest that has not been declared;

- Detailing the range of actions that could be taken by the Chair if a committee member has a conflict of interest;

- Strengthened provisions for the management of gifts and hospitality including prompt declarations and a register of gifts and hospitality that can be accessed by the public. Gifts and hospitality were not explicitly mentioned in the 2014 guidance.

- CCGs should undertake an annual audit of conflicts of interest management as part of the internal audit and include the audit findings in the annual end-ofyear governance statement.

- CCG employees, committee members and practice staff involved in CCG business must undertake mandatory online conflicts of interest training provided by NHSE.

The revised guidance ${ }^{18}$ made clear that in situations where an individual has a direct financial interest that can lead to a serious conflict, the CCG should consider whether this interest can be managed. If not, it may be 
appropriate to prevent the continuation of the circumstances that facilitated the conflict. This may mean the individual discontinuing their role in the CCG or preventing such an appointment in the first place. Moreover, an individual with an interest in an organisation that provides or is expected to provide substantial services to the CCG should not be a member of the CCGs' GB or any committee or subcommittee, particularly if the conflict prevents them from effectively performing their role.

The 2016 guidance required CCGs to implement robust systems to identify and manage conflicts of interest to ensure that decision making is 'transparent and fair'. The guidance advised CCGs that this could be achieved by keeping accurate records and involving the public in primary care commissioning committee (PCCC) meetings. Provider engagement in service specification and procurement should also be 'transparent'.

The revised guidance ${ }^{18}$ stipulated that register(s) of interest must include:

1. All CCG employees including full-time and part-time staff, including those on short-term contracts.

2. All members of the CCG's committees and subcommittees/subgroups.

3. All members of the CCG including GP partners and any person directly involved in decision making of the CCG.

Following our fieldwork, in February 2017, NHSE published further NHS-wide guidance, which came into force in June 2017 to complement the statutory guidance for CCGs. ${ }^{20}$ The revised guidance ${ }^{18}$ was slightly refined to ensure consistency with the NHS-wide guidance. ${ }^{21}$ This meant that CCGs were required to include only decision-making staff on the published register of interests.

Against this background, we undertook a study of primary care co-commissioning including CCGs' approaches to managing conflicts of interest as they took on this additional responsibility. We explored how
CCGs responded to this guidance and how the resulting processes played out in practice.

\section{STUDY DESIGN AND METHODS}

\section{Overall research design}

This research was undertaken as part of a wider study on primary care co-commissioning. ${ }^{22}$

We undertook an exploratory approach, combining analysis of policy documents, telephone surveys with a sample of CCGs and detailed case studies. During the first stage of our field work, the 2014 statutory guidance for CCGs on managing conflicts of interest ${ }^{17}$ was in place. The revised 2016 guidance ${ }^{18}$ came into effect while we were still undertaking field work. This allowed us to observe how the new guidance was responded to during meetings and to explore it with our interviewees.

\section{Review of CCG application documents}

In order to explore the uptake of primary care co-commissioning nationally (April-May 2015), we obtained from NHSE (with CCGs' agreement) 147 applications from 150 CCGs (some CCGs had submitted a joint application with their neighbouring CCGs). We reviewed these applications and created a database of CCGs, listing their levels of co-commissioning responsibility, contact details of a named person responsible within each CCG and detailed information on what was stated or included in their application.

\section{Telephone surveys}

From the database, described above, we selected a sample of CCGs based on various criteria to target for two telephone surveys. The first telephone survey was conducted at 1year following the policy announcement (JuneAugust 2015). Our sampling criteria included: level of co-commissioning responsibility, regional area the CCG belonged to, size of CCG, urban versus rural CCG and

Table 1 Number of responses from level 3 (delegated responsibility) and level 2 (joint commissioning) telephone surveys

\begin{tabular}{lllccc}
\hline Levels & Regions & $\begin{array}{l}\text { Number of CCGs taking } \\
\text { over responsibility from } \\
\text { April 15 }\end{array}$ & Sample CCGs & $\begin{array}{l}\text { Total response } \\
\text { from the first } \\
\text { survey }\end{array}$ & $\begin{array}{l}\text { Total response } \\
\text { from the second } \\
\text { survey }\end{array}$ \\
\hline Delegated & North & 24 & 7 & 7 & 2 \\
(level 3) & Midlands \& East & 26 & 8 & 8 & 4 \\
& London & 6 & 2 & 2 & 1 \\
& South & 8 & 3 & 3 & 5 \\
Total (level 3) & & $\mathbf{6 4}$ & $\mathbf{2 0}$ & $\mathbf{2 0}$ & $\mathbf{1 2}$ \\
Joint & North & 31 & 10 & 6 & 6 \\
(level 2) & Midlands \& East & 16 & 6 & 3 & 1 \\
& London & 20 & 3 & 1 & 0 \\
& South & 20 & 7 & 7 & 1 \\
\hline Total (level 2) & & $\mathbf{8 7}$ & $\mathbf{2 6}$ & $\mathbf{1 7}$ & $\mathbf{8}$ \\
\hline
\end{tabular}

CCGs, clinical commissioning groups. 
those undertaking collaborative commissioning with a neighbouring CCG(s) or having submitted a joint application. We repeated the survey at 2 years following the policy announcement (August-October 2016) and contacted the same sample of CCGs. Between the first and second surveys, we found that a number of people had left the organisation or changed job roles, which meant that recruitment was more problematic for the second round. Moreover, some of the CCGs we spoke with changed their levels of responsibilities from greater involvement to joint or delegated or from joint to delegated. Table 1 provides an overview of the telephone survey sample and response rates. The telephone interviews were conducted at the University of Manchester and the London School of Hygiene \& Tropical Medicine. The telephone interviews were audio recorded and were less than 1 hour in duration. Results from both phases of the survey were tabulated into a database for analysis. In this paper, we concentrate on the responses from CCGs that opted for level 3 (delegated responsibility) and level 2 (joint commissioning) as they were more likely to face conflicts of interest issues than level 1 (greater involvement) CCGs, who would have 'influence' but not take the lead in shaping primary care locally. ${ }^{22}$

\section{Case studies}

We conducted qualitative case studies in four CCGs nationally. The selection of the case study sites was informed by the findings of the first telephone survey. Table 2 details the case study sites and data collected in each site. Once access to sites had been agreed, we had some difficulty in accessing a full range of meetings, with some sites reluctant to allow us to attend non-public meetings. Concerns included issues of confidentiality and concerns about the sharing of commercially sensitive information. However, in all sites, these concerns were eventually overcome, allowing us access to a full range of relevant types of meetings.

Our observations focused mainly on meetings associated with primary care co-commissioning, which included the PCCC and its subcommittees or subgroups. These varied in composition and designation, with descriptors including strategy committee, operational committee and quality committee. However, these names were not related to functions in any standard way, with no clearly discernible differences between a subgroup labelled 'strategy' and one labelled 'operational'. We attended a total of 74 meetings (approximately 111 hours of observations). Field notes were made during and after the meeting observations.

We conducted 42 face-to-face interviews across the four sites with members of the PCCC such as the lay chair, primary care manager, head of contracts, head of quality, head of estates, head of engagement, local medical council (LMC) representative and director of Healthwatch. We also interviewed the CCGs' GB chair, accountable officer and chief finance officer. These interviewees were purposively selected based on their knowledge of and involvement in primary care co-commissioning. No interviewee that we approached refused to participate.

Experienced qualitative researchers (VM, IM, LW-G, $\mathrm{OG}$ and $\mathrm{DB}$ ) conducted the interviews and meeting observations. The researchers had no relationship with the research participants other than that related to the research. Participants were approached by email or telephone in the first instance, were given written documentation describing the aims of this research and given an opportunity to ask questions prior to giving their consent to participate. The face-to-face interviews and meeting observations were generally held in the CCGs' offices, with only the interviewer and interviewee present. The face-to-face interviews lasted approximately 1 hour and were audio recorded and transcribed. No repeat face-toface interviews were conducted as all the necessary information was collected.

For data analysis, an initial coding framework was developed from our reading of relevant policy documents and our prior understanding of relevant literature. This was supplemented by the inductive coding of additional themes arising from the analysis, with six authors (VM, IM, KC, LW-G, DB and AC) involved in discussing and agreeing these codes. Major themes included in the final coding framework were conflicts of interest, governance and structures, internal and external relationships, main areas of activity and service and problems encountered since taking on co-commissioning responsibility. The coding framework was used to code the interviews and meeting observations by five of the authors (VM, IM, LW-G, OG and DB) using the NVivo software.

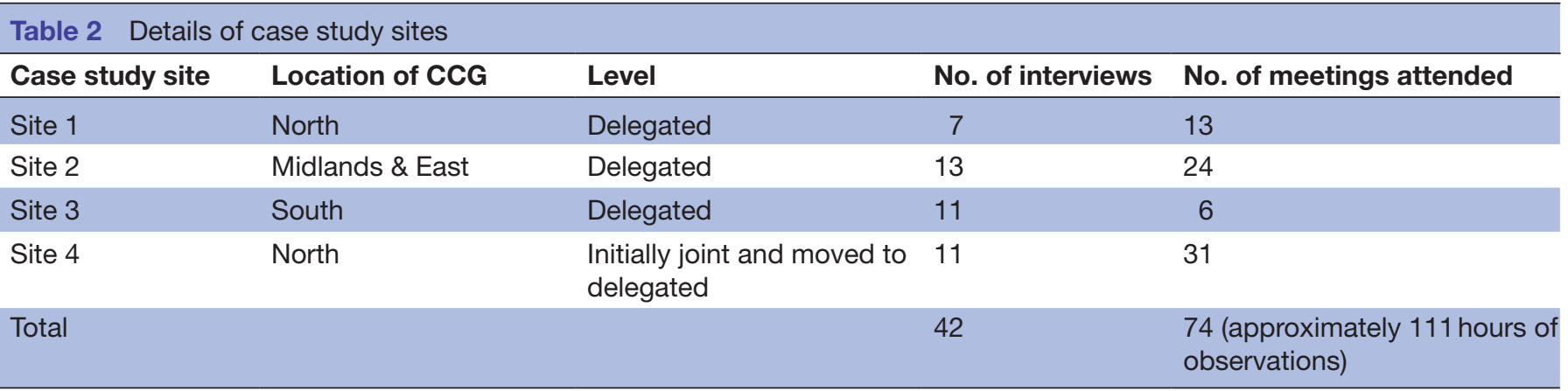

CCGs, clinical commissioning groups. 


\section{RESULTS}

Following the structure of the NAO report, we discuss our results in terms of the accountability, control and assurance arrangements in place to prevent and manage conflicts of interest, the risks of conflicts of interest and the management of conflicts of interest in practice.

\section{Accountability, control and assurance arrangements}

A number of interviewees and telephone survey respondents shared their views on the NHSE statutory guidance on managing conflicts of interest for CCGs, particularly on the revision of the guidance published in 2016.

During the second telephone survey, five CCGs discussed the NHSE conflicts of interest guidance. Of these, two CCGs explicitly referred to the revised guidance $^{18}$ published prior to the second telephone survey, and we do not know whether the other three CCGs were also referring to the revised guidance. While some interviewees raised the topic of the revised guidance, it was not discussed in all of the face-to-face interviews, suggesting it was not an issue of great concern.

Interviewees told us that a revision of the 2014 guidance $^{17}$ was necessary, as there was still some confusion regarding procedures for conflicts of interest:

But it's still sometimes not everybody gets where there's a conflict of interest and what you should be doing in terms of declaring that conflict, managing that conflict, even down to business support to that committee, knowing when they have to make it absolutely clear in the minutes that that person has (withdrawn from the meeting) that person has come back into the meeting for the very reason of conflict... (Lay member ID 15)

One respondent from the second telephone survey felt that the revised 2016 guidance was tighter than the original 2014 guidance. Similarly, a case study interviewee voiced the opinion that the revised guidance was an improvement on the original, which had been interpreted inconsistently by CCGs.

Well, before what we did was we only looked at people involved in commissioning from member practices, so we went to networks. We didn't have a register of all GP partners. The new guidance is every single member of staff, whether they're a GP or whether they're a cleaner, they will be declaring their address and they'll be published, so we're waiting for that. (Manager ID 13)

While the revised guidance clarified some issues, there remained some confusion over terminology, including what constituted a 'close' relative or friend. During the second telephone survey, one respondent interpreted the guidance as suggesting that GPs do not need to leave the room for minor decisions, but the chair of their PCCC had decided that GPs should not participate in the discussion or decision, even if the conflict was minor. This suggests that even the revised guidance lacked clarity and was open to different interpretations.
One interviewee (lay member ID 15) described the revised guidance as a 'kneejerk reaction', which was too encompassing and even unreasonable, and implied there would be a push back by CCGs, particularly as it was becoming too onerous to update the register of interests and register of gifts and hospitality.

There was also a concern that such an all-embracing policy would create suspicion when people did not declare an interest, particularly due to the 'incestuous' (lay member ID 15) nature of the medical profession:

But when somebody comes back on no declarations of interests you think you must have some outside declarations of interests somewhere, you must have something to do with somebody. (Lay member ID 15)

During the second telephone survey, two CCGs spoke about assurance more broadly. One respondent said that they highlighted any conflicts of interest in the quarterly assurance to NHSE. Another respondent spoke of the need to demonstrate the adoption of a similar assurance process for GP practices as for other providers.

In summary, the main assurance mechanism highlighted by our data was the NHSE statutory guidance on managing conflicts of interest. Our findings suggest that while the revised conflicts of interest guidance was an improvement on the original, there was scope for further progress in clarifying terminology and procedures outlined therein.

\section{Risks of conflicts of interest}

The risk of conflicts of interest arises from the public stewardship role that GPs assume in their position of commissioners of primary care. This differs fundamentally from their role as private providers contracted by the NHS to deliver primary care services. Our respondents told us that they perceived the risk of conflicts of interest concerned processes such as: obtaining clinical input for contract and service specifications; supporting the development of GP provider organisations; GPs' influence over discussions and decision-making; and GPs' perceived bias towards primary care.

You see, as independent providers there is no obligation on them [GPs] to be publically accountable in the same way as we are as a CCG. However, if they're using public money there is an obligation on them to explain how are we best going to use it. So there is this dichotomy here in the NHS between a public service being run by independent contractors, which has always been, I think, in a sense, a difficulty for the NHS ever since it was formed in 1948. (Lay member ID 14)

Thus, a central issue was the public interest and ensuring value for money for public funds. It was regarded as necessary for GPs, as the custodians of public funds, to persuade the public that the CCG had no vested interests. In both the first telephone survey and the faceto-face interviews, the perception of a conflict of interest 
was viewed as being just as serious as an actual conflict of interest:

I think it's something that we are very conscious of, not just that it doesn't happen but that it is perceived not to happen either because I think if we ever step away from that, it could make the whole thing fail, you know what I mean? If people perceive that there is unacceptable goings on, then we failed even if there is or there isn't. So I think it's really important that we are very, very robust in our discussions, recognising that that conflict of interest is there and managing. (LMC representative GP ID 30)

Part of the rationale for transferring responsibility for commissioning primary care to CCGs was to use their knowledge of local population needs. This meant that GPs' conflicts were an inevitable consequence of engaging them in decision making about healthcare provision:

So... and the whole point is that you should be conflicted because if you're conflicted it means you know about your subject. (CCG chair GP ID 8)

Interviewees viewed conflicts of interest as something to be managed rather than eliminated, a view echoed in our first telephone survey. CCGs had to weigh using the important input of GPs in terms of knowledge of local health issues against potential conflicts stemming from GPs as members of the organisation holding their contracts.

It's a balancing act as well, between what enables the CCG to function as a member led organisation, a clinical led organisation and how we make sure that we are managing it so that central providers are not given an advantage in a competitive world really. It's a balancing act and as I say there's not one size fits all, I think it's always going to be difficult for us and primary care commissioning has made it more difficult. (Manager ID 43)

During the second telephone survey, the majority of CCGs responded that they had had to deal with conflicts of interest. Risks of conflicts of interest identified during both telephone surveys arose from the relationships with member practices and the performance management of practices. Additional risks stemmed from the design, review and specification of contracts and services.

One interviewee (manager ID 45) described how almost all discussions about primary care by the CCG had a financial and workload impact on practices and yet it was felt that GPs had to be involved in those discussions. A clear example of this was how to obtain clinical input to a new outcome-based incentive scheme as described during a face-to-face interview:

I know that the [name of a primary care initiative], there was a huge conflict of interest around that obviously, because we couldn't necessarily let GPs write their own contract, but we also needed their input into it. So, we did some workshops and we developed something, and then it went to directors, and they looked at it, and then it went to Co-commissioning Committee to be signed off. (Manager ID 25)

CCGs also had to avoid giving their GP members a competitive advantage. A particular challenge was faced by the case study sites with GP federations (groups of practices that form a consortium to work together as providers). In site 2, some federations required help and support in the early stages of their establishment and the CCG had to be careful about drawing a clear line in terms of their input, as the federation was also a potential provider.

So the plan is to try and meet with the federation to say, okay, well, what support would you like to then be able to look at that against potential conflict of interest to see where the middle ground is that can actually support them with that. Because I think without that support, again, it's going to be very difficult for them to deliver all the requirements that are needed for them. Yeah, but then would you do something like write a bid or a tender for an organisation when you are a commissioning...for a provider when you are a commissioning organisation? That's where it... because that's what they want, that's what they need, because they haven't got that experience. (Manager ID 24)

For some GPs and CCG employees, it was not immediately evident why conflicts of interest should be an issue for concern. Conflicts of interest were seen as a long-standing and inevitable consequence of GP involvement in commissioning, which could be managed by a combination of transparency and careful management of committee membership:

I mean, you know, even before we took on cocommissioning we did commission some services from primary care which are called locally commissioned services. And we have, you know, in developing those services; we have clinical leads who are also providers. So, it is something that you are always aware of. But, you put, kind of, controls into place. So, when we were developing some of those locally commissioned services our clinical leads take, you know, help to develop the clinical side of it, but, we don't discuss finance until it goes to the procurement committee or something like that. So, it's, you know, I suppose you just have to deal with it as well as you can...but I don't see it as a huge problem, conflict of interest. (Manager ID 35)

This resonated with a view that 'GPS are ultimately trustworthy people and, therefore, you know, can rise above conflicts and make decisions' (CCG chair GP ID 38). Similarly, a respondent from our first telephone survey claimed that conflicts of interest were not a risk because there was official guidance ${ }^{17}$ for this. 
During a conflicts of interest training session in site 4, one GP attendee pointed out that with his practice partners, he had to make decisions that would affect practice income. It was not clear to him how making decisions with the CCG that affected income differed from practice decision making. This suggests that this GP did not understand his stewardship role.

During our fieldwork, we became aware of potential conflicts of interest issues arising from GPs' influence over discussions and decision making as well as GPs' bias towards primary care. An interviewee who is a lay member of the PCCC in site 2 admitted that GP representatives have an influence on the lay and non-executive membership in decision making:

We may be non-executives taking decisions but we're here in the presence of two other constituencies. One is patient representatives and so on. The other is the clinical input from GPs and GPs' organisations, like the LMC. They have an influence on us. They may not have executive power, but they have an influence. (Lay member ID 14)

On one hand, it is perhaps not surprising that GPs have an influence, as their role is to provide clinical input and knowledge of local population needs. On the other hand, this influence can constitute a conflict of interest if GPs manipulate decision making to serve their own interests, rather than those of the populations they serve.

An executive member of the PCCC in site 3, when discussing decision making about primary care funding, recognised the need for awareness of the influence GPs and indeed practice managers have on other committee members:

and obviously you have to be aware that there's a conflict there, because the Primary Care Committee, albeit that the clinical representation is outweighed by the main membership, but you know, that if the conversation is being influenced by GPs [and practice managers], they've got a conflict of interest there, because they've got two hats on. (Manager ID 34)

Another interviewee in the same site went further in recognising the difficulty of dealing with this less obvious form of conflict of interest:

I don't think that overt conflicts of interest are a problem I think that they're well recognised and managed in meetings. I think it's much more difficult the relationships between practices and how that can influence and the relationships between clinicians and practice managers. I think it's a challenge to then to be able to park all of that and I would recognise how difficult that could be. And I don't know how if I'm honest, I'm not sure how easy that would be, that is going to be going forward. I think there's a potential there for some influence on decisions that isn't overt but that does happen and I think we have to be very careful about that. (Manager ID 37)
Interestingly, this 'soft power' was less apparent in site 1, which employed an independent GP, implying that GPs' pre-existing relationships with other committee members may be an important conduit of influence as evidenced by the views of (manager ID 37) outlined above.

There was also concern about conflicts of interest arising from GPs' natural predisposition towards primary care:

So if they [GPs] had a choice about do I spend this money on primary care or secondary care or give it to public health or something? They're going to say primary care. So even if it's not an obvious conflict of interest, it's a not obvious conflict, you know, it's just... so how do we get around that? What do our hospital colleagues think around our conflict of interests, you know, if we go now in our contract and say we're taking $£ 5,000,000$ out of the hospital, because we're going to spend it on more GPs and we're going to have less secondary care commissions....I think they would then worry about the conflict of interests... if push came to shove, to make it quick and make a decision about do we [do] this in primary care or do we do this in secondary care? And I think hospitals then would [cry foul] about the conflict of interests on that. (Manager ID 42)

We observed evidence of this desire for GPs to prioritise investment in primary care during the observation of a GB meeting in site 4 . The context of the discussion was the financial position of the CCG and the risk of a deficit in the overall budget, despite the requirement for the CCG to break even. GP members voiced resistance to using the underspend of the primary care budget to prop up secondary care and achieve overall financial balance.

The use of robust evidence-based information in decision making can help to avoid bias on the part of clinical and non-clinical committee members as described by an interviewee in site 3 :

there have been instances where for example there was the LMC representative has contributed in ways which I would have ruled inappropriate...... I think we have to be very careful about that. And actually the instances I'm thinking of that are of concern not simply to the public but to the decision-making process I would say in terms of equality and parity across the GP membership in this CCG. So I think it's about getting robust evidence-based information to the committee and making decisions on that basis, rather than off-the-hoof comments or suggestions about particular practices and whether they may or may not be viable in fiveyears, for example. (Healthwatch representative ID 29)

Conflicts of interest also posed a problem for committee members other than GPs and practice managers, including lay members. During our meeting observations in sites 1 and 2, there were instances where the lay chair of the primary care committee was conflicted and had to 
hand over the chair to another lay member. In site 1 , the conflict arose as the chair (who was substituting for the usual chair who was on leave) was a patient at a practice under discussion for the relevant item. Although the new chair suggested the former chair could have participated in the discussion but not record a vote, the latter declined following a discussion with the patient representative group of the relevant practice.

In general, the risks of conflicts of interest were recognised and seen as inevitable and something to be managed rather than avoided altogether. The risks of conflicts of interest arose mainly from the tension arising from GPs' roles as both commissioners and providers of services. Nevertheless, lay members also faced risks of conflicts of interest, primarily arising from being consumers (ie, patients) of primary care services.

\section{Management of conflicts of interest}

Given the awareness of the risks of conflicts of interest, we investigated how CCGs managed conflicts of interest in practice and the extent to which procedures and practices varied both within and between CCGs.

We found that our case study CCGs had implemented the 2014 NHSE guidance on managing conflicts of interest ${ }^{17}$ that was in place when we commenced our fieldwork. In order to address conflicts of interest, CCGs revised their governance arrangements and structures. Our case study CCGs each established a separate committee for primary care commissioning-the PCCC. This committee is a decision-making committee and is autonomous from the GB. Although there is some overlap in the membership of the GB and PCCC, an important difference is that a lay member chairs the PCCC. Table 3 outlines the common arrangements to manage conflicts of interest that are in place in our case study sites.

Data from both telephone surveys indicated that the most commonly cited way to manage conflicts was by declaring any conflict at the beginning of the meeting. In the first telephone survey, one respondent had decided to

\section{Table 3 Management of conflicts of interest}

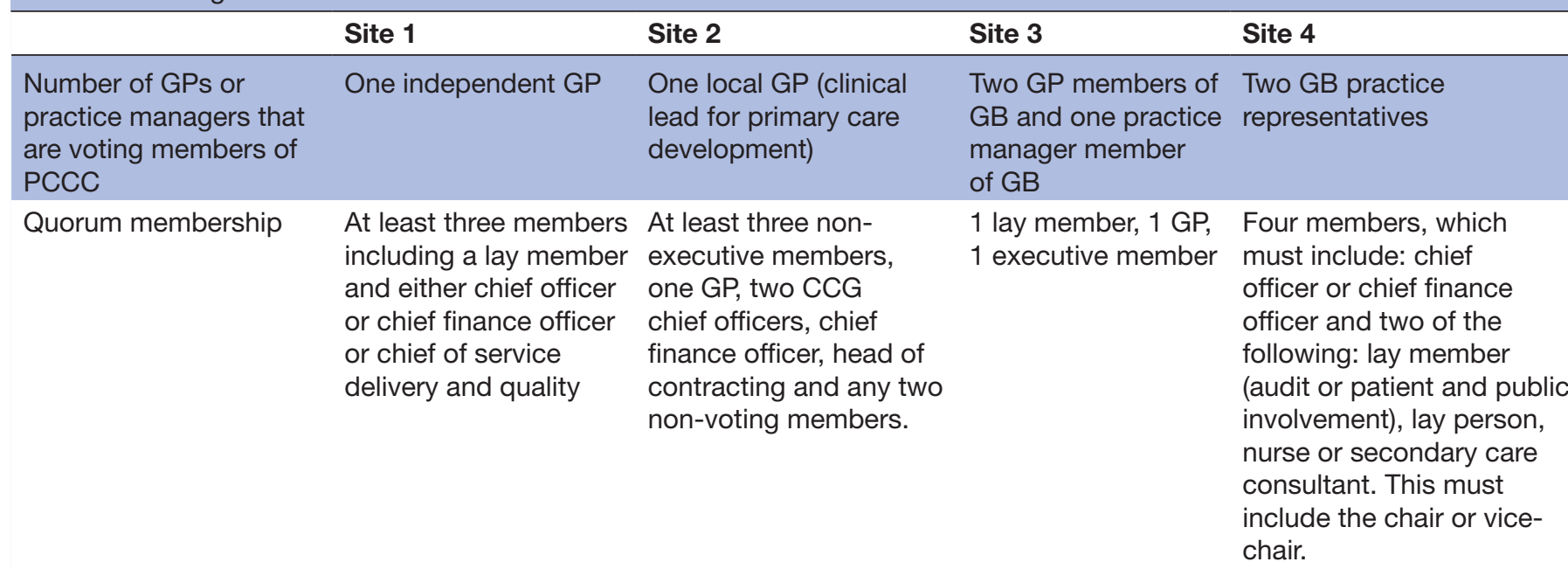

\begin{tabular}{|c|c|c|c|c|}
\hline $\begin{array}{l}\text { Hold meetings of the } \\
\text { PCCC in public and } \\
\text { publish the minutes of } \\
\text { these minutes on their } \\
\text { websites }\end{array}$ & Yes & Yes & Yes & Yes \\
\hline $\begin{array}{l}\text { Independent clinical } \\
\text { input }\end{array}$ & $\begin{array}{l}\text { Independent GP from } \\
\text { another area } \\
\text { Secondary care doctor/ } \\
\text { registered nurse }\end{array}$ & $\begin{array}{l}\text { Secondary care doctor/ } \\
\text { registered nurse }\end{array}$ & $\begin{array}{l}\text { GP members } \\
\text { from different } \\
\text { geographical areas } \\
\text { Secondary care } \\
\text { doctor/registered } \\
\text { nurse }\end{array}$ & $\begin{array}{l}\text { Independent GP from } \\
\text { another area } \\
\text { GP members from } \\
\text { different geographical } \\
\text { areas } \\
\text { Secondary care doctor/ } \\
\text { registered nurse }\end{array}$ \\
\hline $\begin{array}{l}\text { Published register of } \\
\text { interests on website }\end{array}$ & Yes & Yes & Yes & Yes \\
\hline
\end{tabular}

CCG, clinical commissioning group; GB, governing body; GP, general practitioner; PCCC, primary care commissioning committee. 
declare interests at the beginning of the meeting and for each individual item in the meeting. A different respondent claimed that they had no concerns with conflicts of interest as they declared everything and had been as transparent as they could. They thought that the issue of conflicts of interest had been exaggerated. We observed that all of our case study sites had processes in place for members to declare any conflicts of interest at the outset of the meeting.

Data from both telephone surveys and the case studies revealed that CCGs pursued different approaches to addressing conflicts of interest following declarations. It was evident that there was a lack of clarity regarding what actions to take to manage conflicts of interest, and there was much variation in practice at the local level.

During the first telephone survey, some respondents told us that they had decided not to allow GPs to vote on issues where they were conflicted, while others decided not to allow committee members (including GPs) who had possible conflicts to participate in meetings at all. One respondent argued that they believed it was important to have GPs in the room and they tried to reduce conflicts of interest by having GPs with a different contractual arrangement sitting in that meeting. Another respondent described managing conflicts in other committees by putting decisions to the PCCC if the other committee could not reach a decision due to conflicts of interest.

In our case study sites, we observed a lack of consistency in the approach taken both within and between sites. In some instances, the conflicted individuals left the room for the entirety of the discussion and vote for the relevant item. In others, the individuals either remained in the room to contribute to the discussion but not vote, or remained in the room but did not participate in the discussion or vote for the relevant item. Some sites deemed it acceptable for the conflicted individual(s) to stay in the room despite exclusion from the discussion and/or vote when the meeting was in public. The appropriate action taken following a declaration did not appear to be consistent but rather depended on the particular item under discussion. This finding also emerged from the second telephone survey, with one respondent describing the need to deal with conflicts of interest on a case-by-case basis. Inevitably, GPs were sometimes involved in discussions about funding or contracts as illustrated by the following quotes from our case study sites:

but if you look at some of the business we've done in the last few weeks with [name of provider] which was the APMS practices I'd said that was being reprocured, you know; that was a classic example of one where we could stay in the room, make the decisions and everything because none of us were conflicted because it's not our practice, it's not our contract, it's nothing. Then, when you move on to the PMS schemes, where we're talking about, you know, giving money to the [number of] practices, essentially we go out. (CCG chair GP ID 38) with the conflict of interest policy, they would be out of the room if they were directly conflicted, if they were discussing, I don't know, for example, an estates issue or funding that affected their practice or their locality directly. But if it came to a vote around overall funding pot for primary care or new initiatives for primary care, the GPs are in the minority there. And I think that's fine and that's good. (Manager ID 33)

Some flexibility in approach was deemed necessary in order to avoid an impasse in the business of the committee as evidenced by the following example where all GPs left the room prior to a discussion about a contract with no committee member remaining to provide clinical input:

we were discussing minor surgery and the minor surgery contract to provide minor surgery for our patients. And that was quite a big contract, probably worth several hundred thousands of pounds, if not more. So it was a major contract which had to be approved by governing body, however, all of the GPs there, or themselves, provide minor surgery for our patients, and therefore, we were all directly conflicted. What happened was, that in fact at that stage, almost to be seen to be cleaner than clean, all the GPs left the room. But then of course, we said well firstly that seemed very silly, because it was a public meeting anyway, so if it was a public meeting then they could've still stood at the back. The problem was, it was then taken over that there were no clinicians left in the room, so we were therefore discussing... are you a clinician yourself? No, ok, so therefore, the remaining group are discussing the pros and cons of a minor surgery contract without any clinician being in the room. So we said well that is actually stupid, how can they make the right decision when there is no one to ask for advice? So we said what should have actually have happened was that we should've all stayed in the room and said that we can take no part in active discussion, however, we are here for advice if you need that advice, but we can only respond to questions if asked by the independent members. (GP ID 17)

Interviewees recognised the important role of the lay membership of the PCCC in terms of their independence and ability to challenge other members:

We recruited a new lay member particularly to take responsibility for primary care co-commissioning so that we could separate it out from other business within the CCG because of the conflict of interest for our GPs. (CCG accountable officer ID 28)

The attendance and active participation of non-clinical members including executive and lay members was also viewed an important bulwark against potential conflicts for clinical members when their input was required:

we were talking about winter access and schemes and he was, you know, I'm so conflicted in this 
conversation and it was a development conversation and it was just, like, well, you're not the only person that's sat in this room, there are other people in it, we need a clinical view about how would this work in practice, but you're not the one that will make the decision on it and there are other people in this room that will help you manage your conflict. (Manager ID 46)

There was also an understanding that declarations of interest were the responsibility of the affected committee member, and there was an onus on other committee members to bring the conflict to the attention of the committee and for committee members to challenge each other about the conflict:

people have got that opportunity to challenge, but I don't... so if I'm sat in quality safety committee and I'm aware that somebody hasn't declared and I think there's a conflict, then I will call that out in the meeting and we'll have a conversation about how do we handle it? And it'll be documented and that's what people do, yeah. (Manager ID 46)

While CCG senior management recognised that conflicts of interest were an issue, they felt confident that the governance structures and policies put in place to address and manage conflicts of interest were adequate.

So they're there, without a shadow of a doubt, I think we're strong in terms of the management of conflicts of interest in this organisation, I think [name] is very much keeping everybody abreast of change around, you know, the policy around it, we're pretty tight in our committees about how we manage the conflicts and always have been prior to the fully delegated. [Manager ID46]

we were, you know, we were going into a different world of actually having a transactional relationship with the GPs, which could sometimes be tricky when they are members. But, by setting up the PCCC, we took that conflict of interest out. (CCG chair GP ID 27)

Nevertheless, during the second telephone survey, four CCGs viewed the management of conflicts of interest negatively, describing the processes in place as 'cumbersome', 'fairly extreme' and 'too robust'. They argued that this led to a diminution of the clinical perspective in the CCG, resulting in limited development of primary care. During our interviews, it emerged that GP members have had to adjust to the new governance arrangements and additional scrutiny that has arisen because of co-commissioning and this was seen as a big change for them. The GP membership were not always happy with the new policies.

sometimes the GP membership may feel they want more involvement or more say in what happens and I think that's where there can be some disharmony or disunity or sometimes frustration or unhappiness that why was this commissioned? Why hasn't my practice had that offer of being able to do this service or that service? Because sometimes possibly they feel if we are a GP member organisation why can't we as a member just decide everything? I think there has to be a middle ground. (GP ID 16)

One respondent from the second telephone survey reflected that while it was relatively easy to set up committees that adhered to the guidance, it was difficult for these committees to make decisions in isolation from the GB. Our interview data revealed that GPs on the GB felt divorced from the PCCC and this caused frustration as primary care was their area of expertise and the separation could inhibit a strategic overview of the CCG. There was also resentment that GPs did not create the issue of conflicts of interest yet they were seemingly to blame for it.

The cynic in me will say well the government created... we didn't create this ourselves, the government created this system, they brought it up and then said that you need to manage the conflicts of interest. But they created the conflicts of interest in the first place. I mean, they created a body because they specifically wanted to do so, which has a majority of GPs voting on it. They said that they wanted to hand down Primary Care Commissioning, and then said well now you've got all these conflicts of interest, and look at all the rotten things that you are doing. So well, they created the body in the first place. (GP ID 17)

However, it was felt that the procedures were necessary, even if they were not popular among everybody:

But we have the conflicts of interest stuff and we need to look independently of these things and we've made the right decisions and some of them might be tough decisions and you can't always give people what they always want. (Manager ID 42)

To summarise, CCGs revised their governance arrangements and procedures in order to manage the greater risk of conflicts of interest arising from primary care co-commissioning. Declarations of interest during meetings were common, but there generally lacked a consensus about the appropriate approach to take following declarations. Both managers and GPs expressed negative views concerning the management of conflicts of interest.

\section{DISCUSSION AND CONCLUSIONS}

In response to the heightened risk of conflicts of interest from CCGs commissioning primary care, NHSE published guidance for CCGs on managing conflicts of interest prior to the delegation of responsibilities and subsequently strengthened this guidance. The 2016 revised guidance stressed transparency in terms of declarations and registers of interest, lay membership of the PCCC, conflicted members leaving the room for discussions and/or decisions, public involvement in PCCC meetings and robust record-keeping.

While the 2016 revised guidance ${ }^{18}$ improved on the original 2014 guidance $^{17}$ by developing certain areas such as governance and registers of interest, there was still a lack of precision about the use of terms such as 
'appropriate' and 'robust'. The 2016 revised guidance did not clarify what constitutes a 'close friend', a term that continues to cause confusion among users of the revised guidance. There was also some ambiguity in respect of when a conflicted individual should leave the room for discussions and/or decision making.

CCGs have established governance structures to manage conflicts of interest in line with the statutory guidance. Separate committees with decision-making authority for primary care have been established, and these committees have a majority of executive and lay members with GPs in a minority. However, there is a sense of confusion regarding the national rules for managing conflicts of interest, and there is wide variation in local practice and structures. CCGs do not follow a consistent approach following a declaration of a conflict of interest by a GP or practice manager, and in some cases conflicted individuals participated in discussions about contracts and funding, which are areas most susceptible to conflicts of interest. Furthermore, there is an increasing awareness of and concern about the potential for less overt conflicts that are more difficult to identify and address. In particular, GPs and practice managers appear able to affect decision making by exerting influence on non-clinical committee members, notwithstanding governance arrangements limiting their formal participation. Moreover, despite the weight given to the lay membership of the PCCC, lay members themselves are not always immune to conflicts of interest, for example, from being a patient at a CCG member practice. We also found evidence of a more blasé attitude towards the risk of conflicts of interest among some study participants with a lack of awareness of the need for public accountability.

This is the first research to be undertaken exploring the risk of conflicts of interest after CCGs took on responsibility for primary care co-commissioning. We complement four in-depth case studies of CCGs with two representative telephone surveys. Nevertheless, our study was conducted during the early stages of CCGs commissioning primary care. Given the relatively swift implementation process, it can be expected that CCGs were still finding their feet and learning by doing.

This study builds on the NAO Report, ${ }^{2}$ as our data collection took place after CCGs took on primary care co-commissioning, thereby allowing us to investigate how CCGs were managing the increased risk of conflicts of interest, as well as investigating their plans or policies. Our case study approach allowed us to collect richer data as meeting observations enabled us to see how conflicts of interest policies and procedures were implemented in practice. Our findings substantiate the concerns raised by the NAO of the increased risk of conflicts of interest stemming from the introduction of primary care co-commissioning and the difficulty CCGs faced when attempting to respond effectively to these risks.

Our findings from both the case studies and first telephone surveys that suggest that CCGs' concerns about conflicts of interest centred on the perception as well as an actual conflict concur with those of Holder $e t a l^{23}$
Conflicts of interest have been recognised as an important issue since the inception of CCGs and gained renewed attention with the delegation of responsibility for commissioning of primary care. This presents a risk that groups of GPs will commission themselves or their practices to provide services. Therefore, the conflict of interest arising from CCGs commissioning primary care is not akin to conflicts of interest faced by GPs in clinical practice such as those arising from interactions with the pharmaceutical and medical device industries where disclosure is a common although imperfect remedy. ${ }^{24} 25$ Rather, GPs commissioning primary care face conflicts of interest in the form of self-dealing, similar to those faced by managers in business. A range of corporate governance mechanisms has been devised to prevent corporate managers from engaging in conflicts of interest, most notably the use of independent boards to monitor management on behalf of shareholders. Simply increasing transparency by disclosing a potential conflict of interest is not viewed as an adequate measure to prevent undesirable behaviour. Moreover, given the limitations of corporate governance arrangements, it has been found necessary in the corporate world to recognise and avoid circumstances that can potentially give rise to conflicts of interests. A parallel can also be drawn with the conflicts of interests faced by clinicians in the development of clinical guidelines. A recent study ${ }^{26}$ explored how conflicts of interest are disclosed and managed by a national clinical guideline developer, the National Institute for Health and Care Excellence in England. Similar to PCCCs, members of guideline development groups (GDGs) were provided with guidance on what constituted a conflict of interest and declarations were made at the outset of meetings. Nevertheless, the study found that some conflicts of interest, in particular, non-financial interests were difficult to identify, and clinicians were often unaware that their activities constituted a conflict. This posed difficulties given that self-reporting was integral to the conflicts of interest policy. The authors concluded that the mere existence of an explicit policy or guidance is insufficient to address conflicts of interest and recommended that GDG chairs and members receive appropriate training in order to manage conflicts of interest.

Giving CCGs the responsibility to commission primary care created a structural conflict of interest, which cannot be adequately addressed with governance structures and regulations that stress transparency. Simply disclosing an interest does not prevent GPs and practice managers from influencing discussions about primary care, which may undermine their public stewardship role. Moreover, the emphasis on lay membership of the committee may not fully resolve the issues in respect of conflicts of interest, as there are sometimes cases where lay members also face conflicts of interest. Similarly, the management of conflicts of interest using self-policing by means of committee members identifying the potential conflicts of interests of other members can be limited by the personal or pre-existing relationships between committee members. 
The revised statutory guidance ${ }^{18}$ suggests that CCGs should consider appointing retired or out-of-area GPs to the PCCC to minimise conflicts of interest and gain access to clinical advice. Our study shows that the appointment of an independent GP could alleviate the soft power that GP members could have in influencing decision making. Therefore, NHSE should consider mandating the appointment of an out-of-area GP to PCCCs. The guidance on managing conflicts of interest published by NHSE needs to be more precise and less ambiguous so that there is more consistency both within and between CCGs in interpreting this guidance. An additional strategy would be to provide training and support for lay and non-executive members without clinical experience to enable them to make decisions requiring clinical input without relying too heavily on GPs or being influenced by GPs. CCGs could also consider appointing lay members with relevant professional experience to the conflicts of interest guardian role. For example, a CCG that was subject to a conflict of interest investigation in 2016 recently appointed a barrister specialising in professional conduct as its conflicts of interest guardian. ${ }^{27}$

It would be useful to conduct follow-up research examining how CCGs are managing conflicts of interest once primary care co-commissioning is fully embedded in CCGs.

Acknowledgements We are grateful to our participants who were very generous in allowing us access to their organisations.

Contributors All of the authors met the criteria for authorship and contributed to the drafting, revision and finalisation of this paper. $\mathrm{KC}, \mathrm{IM}$ and $\mathrm{AC}$ devised the study. VM, IM, LW-G, OG and DB collected and analysed the data for this study. VM and PA drafted the initial version of the manuscript. VM, PA, IM and $\mathrm{KC}$ were involved in the interpretation of results.

Funding This study was funded by the Department of Health via its Policy Research Programme (grant no 101/0001). The study formed part of the programme of the Policy Research Unit in Commissioning and the Healthcare System.

Disclaimer The views expressed here represent those of the researchers, and not the Department of Health.

Competing interests None declared.

Ethics approval The study received ethical approval from the University of Manchester's Research Ethics Committee (ref 11104).

Provenance and peer review Not commissioned; externally peer reviewed. Data sharing statement No additional data are available.

Open Access This is an Open Access article distributed in accordance with the Creative Commons Attribution Non Commercial (CC BY-NC 4.0) license, which permits others to distribute, remix, adapt, build upon this work non-commercially, and license their derivative works on different terms, provided the original work is properly cited and the use is non-commercial. See: http://creativecommons.org/ licenses/by-nc/4.0/

(C) Article author(s) (or their employer(s) unless otherwise stated in the text of the article) 2017. All rights reserved. No commercial use is permitted unless otherwise expressly granted.

\section{REFERENCES}

1. National Audit Office. Cross-government conflicts of interest. London: National Audit Office; 2015.

2. National Audit Office. Managing conflicts of interest in NHS clinical commissioning groups. London: National Audit Office; 2015.

3. Jensen MC, Meckling WH. Theory of the firm: managerial behavior, agency costs and ownership structure. J financ econ 1976;3:305-60.

4. Smith PC, Street A, Smith PC, et al. Concepts and challenges in measuring the performance of health care organizations. In: Jones $A$, ed. The Elgar companion to health economics. Cheltenham: Edward Elgar, 2012:341-9.

5. Hart O. Corporate Governance: some theory and implications. Econ $J$ 1995;105:678-89.

6. Ingley CB, van der Walt NT. Corporate governance, institutional investors and conflicts of interest. Corporate Governance 2004;12:534-51.

7. Rehbein K. What does more executive discretion mean for corporate governance? Acad Manag Perspect 2009;23:101-3.

8. Nolan RC. The legal control of directors' conflicts of interest in the United Kingdom: non-executive directors following the higgs report. Theoretical Inquiries in Law 2005;6:413-62.

9. Strier F. Conflicts of interest in corporate governance. Journal of Corporate Citizenship 2005;19:79-89.

10. Renders A, Gaeremynck A. Corporate governance, principal-principal agency conflicts, and firm value in European listed companies. Corporate Governance: An International Review 2012;20:125-43.

11. Driscoll D-M. Ethics and Corporate Governance: lessons learned from a financial services Model. Business Ethics Quarterly 2001;11:145-58.

12. The Committee on the Financial Aspects of Corporate Governance and Gee and Co Ltd. Report of the Committee on the Financial Aspects of Corporate Governance. London: Burgess Science Press; 1992.

13. Cafaggi F. Organizational loyalties and models of firms: Governance design and standard of duties. Theoretical Inquiries in Law 2005;6:463-526.

14. NHS Commissioning Board. Clinical commissioning group governing body members: role outlines, attributes and skills. Leeds, UK: NHS Commissioning Board, 2012.

15. Jamal K, Marshall E, Tan H-T. Does disclosure of conflict of interest increase or decrease bias? AUDITING-J Pract Theory 2016;35:89-99.

16. Cain DM, Loewenstein G, Moore DA. The dirt on coming clean: perverse effects of disclosing conflicts of interest. J Legal Stud 2005;34:1-25.

17. NHS England. Managing conflicts of interest: statutory guidance for CCGs. London: NHS England, 2014.

18. NHS England. Managing conflicts of interest: revised statutory guidance for CCGs. Leeds: NHS England, 2016.

19. NHS England. Co-commissioning conflicts of interest audit: summary report. Leeds: NHS England; 2016.

20. NHS England. Managing conflicts of interest in the NHS. Guidance for staff and organisations. Leeds: NHS England, 2017.

21. NHS England. Conflicts of interest in the NHS. NHS Board Paper. Leeds: NHS England; 2017, Report No: PB.09.02.2017/05.

22. McDermott I, Checkland K, Warwick-Giles L, et al. Understanding primary care co-commissioning: uptake, scope of activity and process of change (Interim Report) University of Manchester: Policy Research Unit in Commissioning and the Healthcare System; 2016.

23. Holder $\mathrm{H}$, Robertson $\mathrm{R}$, Ross $\mathrm{S}$, et al. Risk or reward? The changing role of CCGs in general practice. London: The King's Fund, 2015.

24. MacKenzie CR, Cronstein BN. Conflict of interest. Hss J 2006;2:198-201.

25. Tonelli MR. Conflict of interest in clinical practice. Chest 2007;132:664-70.

26. Graham T, Alderson P, Stokes T. Managing conflicts of interest in the UK National Institute for Health and Care Excellence (NICE) clinical guidelines programme: qualitative study. PLoS One 2015;10:e0122313.

27. Clover B. Conflict of interest CCG appoints barrister as governance guardian. Health Serv J 2017 www.hsj.co.uk. 